\title{
ЛИЧНОСТНЫЕ И РЕГУЛЯТОРНЫЕ ПРЕДИКТОРЫ АГРЕССИИ
}

Банщикова Т.Н. (Северо-Кавказский федеральный университет, Ставрополь, Россия)

sevkav@mail.ru

Utinlujmgưuน mú. 28.07.2021

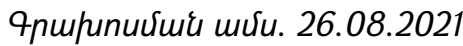

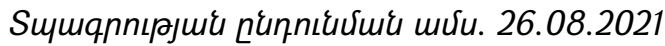

В статье приводятся данные эмпирического исследования регуляторных и личностных предикторов агрессии. В качестве предикторов рассмотрены осознанная саморегуляция, жизненные ценности, социокультурная идентичность и личностные особенности (Big 5) респондентов. Было выдвинуто предположение, что управление агрессией связано с уровнем развития личностно-регуляторных характеристик субъекта, которые имеют свою социокультурную обусловленность. В исследовании приняли участие 278 педагогов из Ставропольского и Краснодарского краев, из республик Северная Осетия-Алания, Карачаево-Черкессия, Кабардино-Балкария. По возрастному составу в выборку вошли педагоги от 20 до 72 лет. Для диагностики использовались: опросник «Стиль саморегуляции поведения», опросник агрессии Басса-Дарки, методика "Определение социокультурной идентичности», Фрайбургский многофакторный личностный опросник, «Морфологический тест жизненных ценностей». Полученные результаты показали, что значимыми предикторами управления агрессией выступают показатели осознанной саморегуляции. Для физической агрессией важным предиктором выступает регуляторный показатель «оценка результатов», а для вербальной агрессии - «планирование». Из числа личностных характеристик значимый вклад в управление агрессией вносят расовая толерантность, региональная идентичность и предрасположенность к стрессовому реагированию на обычные жизненные ситуации, протекающие по пассивно-оборонительному типу.

Ключевые слова: осознанная саморегулячия, агрессия, педагоги, регуляторно-личностные предикторы.

DOI: https://doi.org/10.46991/SBMP/2021.4.2.080

Введение. Современный этап развития человечества характеризуется нарастанием напряжения, тревоги, страха, инициированным новыми вызовами, что часто выступает тригером агрессии с целью самосохранения и 
самоподдержания. «Агрессия - доминирующий способ существования человека <....>, чем более «цивилизованным» становится человек, тем агрессивнее себя ведет. Арсенал паттернов агрессивности не поддаётся учету и исчерпывающему описанию» [6, с. 32]. В данном контексте особый интерес представляют исследования индивидуально-личностных ресурсов резистентности субъекта к деструктивным влияниям. Изучение проблемы возникновения агрессивного поведения невозможно без учета сдерживающих агрессивные проявления фракторов. Обществу необходим эфффективный механизм защиты внутреннего мира, психики человека.

Попытки установления взаимосвязи агрессивных проявлений человека с его регуляторно-личностными характеристиками предпринимались достаточно давно. Отдельные исследования взаимосвязи агрессии с чертами личности, влияющими на специфику ее протекания, осознания, сдерживания можно отметить в работах F. Dorsky. Согласно результатам исследования ученого, высокая социальная тревога (страх социального наказания) снижает вероятность агрессивных проявлений [9]. P.D. Knott, L. Lasater, R. Shuman выявлены признаки внутреннего торможения агрессии у лиц, переживающих чувство вины [10]. Э.Г. Эйдемиллер, С.А. Кулаков, О.В.Черемисин рассматривают агрессивное поведение как своеобразный способ повышения уровня самоуважения [7]. Э. Фромм видит агрессивное поведение с позиции гомеостаза как своеобразный способ саморегуляции [8]. Механизмы саморегуляции субъекта при совершении агрессивных правонарушений в эмоционально напряженных и конфликтных ситуациях рассматривались в работе И.А. Кудрявцева, Н.А. Ратиновой [3]. Необходимость регуляции агрессивного поведения, а также влияние системы осознанной саморегуляции на формирование тех или иных фрорм поведения - конструктивных, социально позитивных, просоциальных, разрушительных, деструктивных, - представлена в работах В.И. Моросановой, М.Д. Гаралевой [4].

Если рассматривать саморегуляцию как сознательный процесс, направленный на управление своей произвольной активностью, как ценностную позицию, которая формируется в процессе социализации - инкультурации, происходящей в конкретном регионе, в конкретное время, в конкретных обстоятельствах, то вполне обоснованной является необходимость установления особенностей конкретного социокультурного пространства, в котором общие характеристики саморегуляции всегда приобретают особый характер [1]. Целью настоящей работы является выявление личностных и регуляторных предикторов агрессии. В качестве регуляторных предикторов рассмотрена осознанная саморегуляция и ее компоненты. В качестве личностных предикторов выступают свойства личности, которые имеют первостепенное значение для процесса регуляции поведения. 
Гипотезой исследования выступило предположение, что управление агрессией связано с уровнем развития личностно-регуляторных характеристик субъекта, которые имеют свою социокультурную обусловленность.

Участники исследования. В исследовании приняли участие 278 представителей педагогической профессии в возрасте от 20 до 72 лет из Ставропольского края (СК) ( $\mathrm{N}=48$ чел.), из Краснодарского края (КК) ( $\mathrm{N}=60$ чел.), из Республики Северная Осетия-Алания (СОА) ( $\mathrm{N}=57$ чел.), из КарачаевоЧеркесской Республики (КЧР) ( $\mathrm{N}=53$ чел.), из Кабардино-Балкарской Республики (КБР) ( $\mathrm{N}=60$ чел.). По гендерному составу выборка представлена на $90 \%$ респондентами женского пола и $10 \%$ мужского.

Методы исследования. Были выделены четыре основные группы методов, которые использовались для оценки исследуемых параметров.

Первый блок - методы оценки регуляторных показателей. Для этого был использован многошкальный тест-опросник “Стиль саморегуляции поведения» (ССПМ). Он позволяет выявить степень развития осознанной саморегуляции и регуляторный профиль ее стилевых характеристик (планирование, моделирование, программирование, оценивание результатов), а также особенности развития регуляторно-личностных свойств (гибкость, самостоятельность, ответственность).

Второй блок - методы исследования личностных характеристик респондентов. Для этого была использована русскоязычная версия Фрайбургского многофракторного личностного опросника (Das Freiburger Personlichkeitsinventar Freiburg Personality Inventory, 1963 г. (FPI)) (Форма B), в адаптации А.А. Крылова, Т.И. Ронгинского, предназначенного для диагностики психических состояний и свойств личности, которые имеют первостепенное значение для процесса социальной адаптации и регуляции поведения. Методика «Морфологический тест жизненных ценностей» (МТЖЦ) В.Ф. Сопова и Л.В. Карпушиной позволяет диагностировать мотивационно-ценностную структуру личности, выявить наиболее значимые для респондента терминальные ценности и те жизненные сореры, в которых эти ценности могут быть реализованы. К основным диагностическим конструктам МТЖЦ относятся терминальные ценности и жизненные сореры.

Третий блок методов - исследование агрессивных проявлений. Опросник Басса-Дарки (A.N. Buss-Durkee Inventory, 1957 г.) предназначен для определения форм агрессивного поведения и личностных черт агрессивности человека.

Четвертый блок - методика «Определение социокультурной идентичности» (ОСКИ) О.В. Крупенко, О.В. Фролова (модифицированный вариант). Методика предназначена для определения социокультурной идентичности и позволяет определить этническую идентичность, региональную идентичность, 
склонность к расизму как сложный и противоречивый комплекс, во многом определяющий или объясняющий поведение конкретного человека в социуме.

Статистическая обработка данных проводилась с помощью программы SPSS 21.0. Был использован множественный регрессионный анализ.

Результаты исследования и их обсуждение. Данные, полученные в ходе проведенного исследования, позволяют дать оценку роли регуляторноличностных характеристик в управлении агрессией. Был проведен множественный регрессионный анализ с целью выявления регуляторных и личностных предикторов агрессии. В результате были построены три регрессионные модели для трех видов агрессии (физическая, вербальная, косвенная). В качестве предикторов рассматривались:

- регуляторные переменные (планирование, моделирование, программирование, оценка результатов, гибкость, самостоятельность);

- показатели социокультурной идентичности (этническая, региональная идентичность, расизм);

- личностные характеристики (застенчивость, открытость, экстраверсия интроверсия, эмоциональная лабильность, маскулинизм - феминизм);

- жизненные ценности (активные социальные контакты, достижения, креативность, высокое материальное положение).

В таблице 1 представлены основные параметры регрессионной модели для переменной «Физическая агрессия». Представленные результаты позволяют утверждать, что предикторами физической агрессии выступают регуляторные процессы «программирование» и «оценка результатов»; регуляторно-личностное свойство «гибкость»; личностные характеристики «застенчивость», «открытость»; жизненная ценность «высокое материальное положение», а также «социокультурная" и "региональная идентичность». Данная модель объясняет 31,6\% дисперсии. Когнитивный показатель саморегуляции «планирование» и регуляторно-личностное свойство «гибкость» имеют положительную связь с физической агрессией. Смеем предположить, что сформированная у педагогов потребность в осознанном планировании своей деятельности, встречаясь с ситуацией неопределенности, многозначности, расценивается как вмешательство в процесс достижения цели и выступает провокационным фрактором агрессии. Сформированная способность перестраивать планы и программы исполнительских действий, потребность получить ресурсы, даже ресурсы других для достижения цели, часто приводит к необходимости использовать физическую силу.

Ингибиторами агрессии выступают пассивно-оборонительный тип реагированию на обычные жизненные ситуации («застенчивость», b=-0,239), сложившиеся культурные ценности и нормы, солидарность с земляками в вопросах взаимодействия с представителями других культур и народностей 
(«региональная идентичность», $\mathrm{b}=-0,216)$, сформированная устойчивость субъективных критериев оценки результатов своей деятельности («оценка результатов», $b=-0,291)$.

Таблица 1.

Регрессионная модель зависимой переменной «Физическая агрессия»

\begin{tabular}{|c|c|c|c|c|c|c|c|}
\hline $\begin{array}{l}\text { Зависи- } \\
\text { мая } \\
\text { перемен- } \\
\text { ная }\end{array}$ & $\mathrm{R}^{2}$ & $\begin{array}{c}\text { Скорректи } \\
\text { рованный } \\
\mathrm{R}^{2}\end{array}$ & $F$ & Значимые предикторы & $b$ & $t$ & $\mathrm{p}$-value \\
\hline \multirow{8}{*}{$\begin{array}{l}\text { Физи- } \\
\text { ческая } \\
\text { агрессия }\end{array}$} & \multirow{8}{*}{$\begin{array}{c}0,316 \\
1\end{array} \mid$} & \multirow{8}{*}{0,2712} & \multirow{8}{*}{7,034} & Программирование & 0,139 & 2,141 & 0,0334 \\
\hline & & & & Оценка результатов & $-0,291$ & $-4,379$ & 0,0000 \\
\hline & & & & Гибкость & 0,186 & 2,844 & 0,0049 \\
\hline & & & & Застенчивость & $-0,239$ & $-3,243$ & 0,0014 \\
\hline & & & & Открытость & 0,206 & 3,278 & 0,0012 \\
\hline & & & & $\begin{array}{l}\text { Высокое материальное } \\
\text { положение }\end{array}$ & 0,256 & 2,895 & 0,0042 \\
\hline & & & & $\begin{array}{l}\text { Социокультурная } \\
\text { идентичность }\end{array}$ & 0,133 & 2,064 & 0,0402 \\
\hline & & & & $\begin{array}{l}\text { Региональная } \\
\text { идентичность }\end{array}$ & $-0,216$ & $-3,294$ & 0,0012 \\
\hline
\end{tabular}

Состав регрессионной модели «вербальная агрессия» включает следующие предикторы: «планирование», «сохранение собственной индивидуальности», «экстраверсия - интроверсия», «готовность к риску».

Вербальная агрессия обусловлена преобладанием у респондентов собственных мнений, взглядов, убеждений над общепринятыми, защитой своей неповторимости и независимости (шкала "сохранение собственной индивидуальности", $b=0,389)$, выраженной экстравертированностью личности $(b=0,276)$, готовностью к риску $(b=0,171)$, недостаточной сформированностью потребности в планировании своих действий и поведения (показатель «планирование», $b=-0,195)$. Готовность к выдвижению и удержанию целей, сформированная потребность в осознанном планировании своих поступков (регуляторный процесс «планирование») выступает одним из значимых предикторов управления вербальной агрессией.

Значимыми предикторами косвенной агрессии выступили шкалы «программирование», «маскулинизм - феминизм», «расовая толерантность», «сохранение собственной индивидуальности». Данная модель объясняет 31,6 \% дисперсии (табл.2). 
Для педагогов непрямые агрессивные действия, программируются (шкала «программирование» $b=0,151)$, т. е. продумываются способы таких действий и поведения для достижения намеченных целей, психическая деятельность протекает преимущественно по мужскому типу (маскулинизм $b=0,163$ ), преобладают собственные мнения, взгляды, защищается своя неповторимость и независимость (показатель "сохранение собственной индивидуальности", $b=0,293$ ).

Убежденность в том, что принадлежность к определенной этнической группе не имеет решающего значение для ограничения прав других (расовая толерантность, $b=-0,134)$, в итоге приводит к сдерживанию косвенных форм агрессии.

Таблица 2.

Регрессионная модель зависимой переменной «Косвенная агрессия»

\begin{tabular}{|c|c|c|c|c|c|c|c|}
\hline $\mid \begin{array}{l}\text { Зависимая } \\
\text { перемен- } \\
\text { ная }\end{array}$ & $\mathrm{R}^{2}$ & $\begin{array}{c}\text { Скоррект } \\
\text { ирован- } \\
\text { ный } \\
\mathrm{R}^{2}\end{array}$ & $F$ & $\begin{array}{c}\text { Значимые } \\
\text { предикторы }\end{array}$ & $b^{*}$ & $\mathrm{t}$ & $p$-value \\
\hline \multirow{4}{*}{$\mid \begin{array}{l}\text { Косвенная } \\
\text { агрессия }\end{array}$} & \multirow{4}{*}{0,3161} & \multirow{4}{*}{0,1303} & \multirow{4}{*}{4,1039} & $\begin{array}{c}\text { Программирован } \\
\text { ие }\end{array}$ & 0,151 & 2,315 & 0,0215 \\
\hline & & & & $\begin{array}{c}\text { Маскулинизм- } \\
\text { феминизм } \\
\end{array}$ & 0,163 & 2,053 & 0,0412 \\
\hline & & & & $\begin{array}{c}\text { Расовая } \\
\text { толерантность }\end{array}$ & $-0,134$ & $-2,007$ & 0,0460 \\
\hline & & & & $\begin{array}{c}\text { Сохранение } \\
\text { собственной } \\
\text { индиви- } \\
\text { дуальности }\end{array}$ & 0,293 & 2,875 & 0,0044 \\
\hline
\end{tabular}

Выводы. Рассмотрение вопроса о роли регуляторно-личностных характеристик в управлении агрессией позволило выявить ряд характерных особенностей.

Во-первых, повышенная идентификация с социальными требованиями, строгое соблюдения этических и этнических норм в поведении и деятельности, сдержанность и уважительное отношение к установленным нормам и ценностям социума могут выступать для педагогов регуляторными механизмами их поведения.

Во-вторых, осознанная саморегуляция является значимым предиктором управления агрессией. При этом важно учитывать, что роль саморегуляции в управлении разными видами агрессии может быть различна. Так, для 
фризической агрессией важным предиктором выступает регуляторный показатель «оценка результатов», а для вербальной агрессии - «планирование». Осознанное планирование педагогом своей деятельности, реалистичность, детализированность планов, устойчивость субъективных критериев и адекватная оценка полученных результатов, оценка причин, приведшие к данному результату снижают вероятность агрессивных проявлений.

В-третьих, из числа личностных характеристик представленной выборки педагогов значимый вклад в управление агрессией вносят расовая толерантность, региональная идентичность и предрасположенность к стрессовому реагированию на обычные жизненные ситуации, протекающие по пассивно-оборонительному типу. Избегание рискованных ситуаций, предпочтение широкому общению узкого круга старых, проверенных друзей, ассоциирование себя с некоей социальной, расовой или этнической группой, повышенная идентификация с социальными требованиями, строгое соблюдения этических и этнических норм в поведении и деятельности, сдержанность и уважительное отношение к установленным нормам и ценностям социума, убежденность в том, что принадлежность к определенной этнической группе не имеет решающего значение для ограничения прав других, - все это выступает регуляторными механизмами агрессии.

\section{Литература}

1. Банщикова Т.Н., Моросанова В.И. Региональная специфика индивидуально-типологических особенностей взаимосвязи саморегуляции и агрессии у педагогов// Вестник Северо-Кавказского федерального университета. 2016. № 1 (52). с. 114 - 121.

2. Берри Д., Пуртинга А., Сигалл М., Дасен П. Кросс-культурная психология. Исследования и применение. Харьков.: Гуманитарный центр, 2007, 560 с.

3. Кудрявцев И.А., Ратинова Н.А. Криминальная агрессия (экспертная типология и судебно-психологическая оценка). М.: Изд-во Московского университета, 2000. 192 с.

4. Моросанова В.И., Гаралева М.Д. Проявление саморегуляции в различных видах агрессивного поведения // Журнал прикладной психологии. 2004. № 6. с. 12 - 19.

5. Моросанова В.И. Опросник «Стиль саморегуляции поведения» (ССПМ): руководство. М.: Когнито-Центр, 2004. 44 с.

6. Семечкин Н.И. Агрессия - доминирующий способ существования человека. Ананьевские чтения - 2011. Социальная психология и жизнь: Материалы научной конференции, (г. Санкт-Петербург, 18 - 20 октября 
2011 г.) / Отв. ред. А.Л. Свенцицкий. СПб.: Издательство СанктПетербургского университета, 2011. с. 31 - 33.

7. Эйдемиллер Э.Г., Кулаков С.А., Черемисин О.В. Саморазрушающее поведение у подростков: пути исследования, проблемы и разработка методов психотерапии // Саморазрушающее поведение у подростков. Л.: Изд-во «Ленинградский психоневрологический институт», 1991. с. $112-117$.

8. Фромм Э. Анатомия человеческой деструктивности. М.: Республика, 1994. $551 \mathrm{c}$.

9. Dorsky F., Taylor S. Physical aggression as a function of manifest anxiety. Psychonomic Science. 1972. № 27. pp. 103 - 104.

10. Knott P.D., Lasater L., \& Shuman R. Aggression-guilt and conditionability for aggressiveness. Journal of Personality. 1974. № 42, pp. 332 - 344.

\section{PERSONAL AND REGULATORY PREDICTORS OF AGGRESSION}

Banshchikova T.N. (North Caucasian Federal University, Stavropol, Russia)

The article provides data from an empirical study of regulatory and personal predictors of aggression. Conscious self-regulation, life values, sociocultural identity and personal characteristics (Big 5) of the respondents were considered as predictors. It was suggested that the management of aggression is associated with the level of development of the personality-regulatory characteristics of the subject, which have their own socio-cultural conditioning. The study involved 278 teachers from the Stavropol and Krasnodar regions, from the republics of North OssetiaAlania, Karachay-Cherkessia, Kabardino-Balkaria. By age structure, the sample included teachers from 20 to 72 years old. For diagnostics, we used: questionnaire "Style of self-regulation of behavior", questionnaire of aggression Bass-Darki, methodology "Determination of sociocultural identity", Freiburg multifactorial personality questionnaire, "Morphological test of life values." The results obtained showed that indicators of conscious self-regulation are significant predictors of aggression management. For physical aggression, an important predictor is the regulatory indicator "evaluation of results", and for verbal aggression - "planning". And in the number of personal characteristics, racial tolerance, regional identity and a predisposition to stressful responses to ordinary life situations proceeding in a passive-defensive type make a significant contribution to the management of aggression.

Keywords: conscious self-regulation, aggression, teachers, regulatory and personality predictors. 